Sokoli Bylbyl, Ibrahimi Gani, Jahaj Qendrim. Differences in short and long passes of midfield footballers. Journal of Education, Health and Sport. 2020;10(2):140-147. eISSN 2391-8306. DOI http://dx.doi.org/10.12775/JEHS.2020.10.02.019

https://apcz.umk.pl/czasopisma/index.php/JEHS/article/view/JEHS.2020.10.02.019

https://zenodo.org/record/3686289

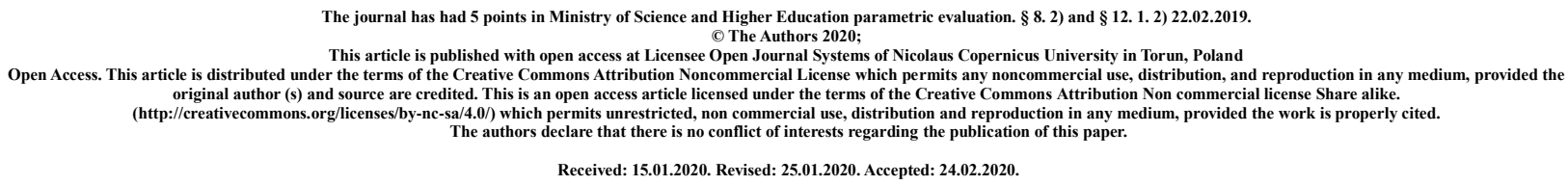

\title{
Differences in short and long passes of midfield footballers
}

\author{
Bylbyl Sokoli \\ University of Prishtina
}

Faculty of physical education and sport

Republic of Kosovo

Gani Ibrahimi

University of Prishtina

Faculty of physical education and sport

Republic of Kosovo

\author{
Qendrim Jahaj \\ University of Prishtina \\ Faculty of physical education and sport \\ Republic of Kosovo
}




\begin{abstract}
Absract
Efficiency in the game of football is possible only if phenomena is systematically defined as it is of primary importance for structuring the basic movements and the technical-tactical elements in the game of football. The main purpose of this research is to compare the midfielders of Superleague and First League of Kosovo in the technical element of the pass which is very significant for the quality of a footballer and especially of a midfielder. To this end, three hypotheses have been put forward which have been partially realized. The obtained results show that the Kosovo Superleague midfielders have shown higher efficiency in these specific technical elements during the game: in total passes, in accurate passes, inaccurate passes, in accurate short passes where Superleague footballers have had fewer long incorrect passes.
\end{abstract}

\title{
Key words: Superleague of Kosovo, The First League, football, technical elements, passes.
}

\section{INTRODUCTION}

All players in a team are important no matter what position they play on the pitch. Everyone in one way or another gives the contribution on the pitch, but possibly midfielders are those who have the main responsibility in the team. Usually in youth football the midfielders are just players playing in the middle of the field. Over time as their technical and tactical skills improve they are subdivided into several types of midfielders: side midfielders, defensive midfielders, central midfielders and offensive midfielders. Midfielders are the ones who link defense with the attack, they are the team engine and are the ones who organize almost all the action. Quality midfielders should have enough quality in order not to think about the ball control but how to distribute it as quickly as possible. Also midfielders should be able to predict what will happen next.

In football the ability to maintain ball possession for a long time enables the team to be more likely to have a favorable outcome at the end of the match. (Hook and Hughes, 2001). The accuracy of this assertion was confirmed in the 2001-2002 Premier League season where 24 matches were compared. Winner teams had far more ball possession than the losers. But it was also found that successful and unsuccessful teams had better possession of the ball when they were losing than when they were winning.

Well-known midfielders are distinguished by their physical, technical-tactical qualities as well as their creativity on the pitch. A very significant and important quality for footballers is especially the passes. Counting passes is easy but it is important who are the best passers and what is the impact on the team.

Usually the best football players are the best passers and all players no matter what position they play should improve this ability. At first glance passes seem simple but is actually very difficult to perfectionate. Passing is part of the technical elements with the ball and is one of the first techniques learned in football. The two known types of passes are: the short passes and the long passes for which this study was conducted. A good pass helps to keep the ball in possession and 
this gives you a greater chance of winning otherwise how is goal expected to be scored if the team does not posses the ball?

Developing the habit of passing is the key factor for successful sports team performance. (Robert Rein, Dominik Raabe, Daniel Memmert, 2017).

\section{PURPOSE OF RESEARCH}

The main purpose of this research is to compare the midfielders of the Superleague and the First League of Kosovo in the technical element of the pass which is very significant for the quality of a footballer and especially a midfielder.

Other goals include: Estimating the number of passes per match in total for both ranks and estimating the number of correct and incorrect based on the above classification.

\section{RESEARCH METHODS}

This research included midfield players from Superleague and the First League of Kosovo in football, the spring season 2018-2019 matches calendar. The data are collected from 5 Superleague matches and 6 First League matches. A total of 60 midfielders were analyzed in these matches, for both ranks diveded in halves 30/30. The following variables were applied to all midfielders: Total passes (TP), Correct passes (CP), Incorrect passes (IP), Short correct passes (SHCP), Incorrect short passes (ISHP), accurate long passes (ALP) and incorrect long passes (ILP).

0-30m -- Short pass

$>30 \mathrm{~m}$-- Long Pass

In this study for the two leagues separately these basic statistical parameters: Arithmetic Average (AA), Standard Deviation (SD), Minimum Value (Min) and Maximum Value (Max). Pearson correlation test was used to evaluate the correlations between variables. Whereas to analyze the differences between the Superleague and First League midfielders T-Test was used to test numerical variables as well as descriptive analysis. 


\section{INTERPRETATION OF RESULTS AND DISCUSSION}

Table 1. Basic statistical parameters of asymmetry and normal distribution of specific variables of the First League in football.

\begin{tabular}{|l|l|l|l|l|l|l|l|}
\hline & $\mathbf{N}$ & Minimum & Maximum & Mean & $\begin{array}{l}\text { Std. } \\
\text { Deviation }\end{array}$ & Skewness & Kurtosis \\
\hline TP & $\mathbf{3 0}$ & $\mathbf{7}$ & $\mathbf{6 6}$ & $\mathbf{2 7 . 1 6 6 7}$ & $\mathbf{1 5 . 5 8 7 5 4}$ & $\mathbf{1 . 2 2 5}$ & $\mathbf{0 . 8 6 8}$ \\
\hline CP & $\mathbf{3 0}$ & $\mathbf{6}$ & $\mathbf{5 4}$ & $\mathbf{1 9 . 7 6 6 7}$ & $\mathbf{1 2 . 9 0 7 3 2}$ & $\mathbf{1 . 3 3 9}$ & $\mathbf{0 . 9 8 3}$ \\
\hline IP & $\mathbf{3 0}$ & $\mathbf{1}$ & $\mathbf{1 9}$ & $\mathbf{7 . 4}$ & $\mathbf{3 . 8 6 4 9 6}$ & $\mathbf{0 . 8 0 3}$ & $\mathbf{1 . 4 0 9}$ \\
\hline SHCP & $\mathbf{3 0}$ & $\mathbf{5}$ & $\mathbf{5 1}$ & $\mathbf{1 7 . 6 6 6 7}$ & $\mathbf{1 1 . 8 5 3 5 1}$ & $\mathbf{1 . 3 3 8}$ & $\mathbf{1 . 0 3}$ \\
\hline ISHP & $\mathbf{3 0}$ & $\mathbf{0}$ & $\mathbf{1 2}$ & $\mathbf{4 . 4}$ & $\mathbf{2 . 6 3 4}$ & $\mathbf{0 . 6 9 7}$ & $\mathbf{1 . 1 7 9}$ \\
\hline ALP & $\mathbf{3 0}$ & $\mathbf{0}$ & $\mathbf{1 0}$ & $\mathbf{2 . 2}$ & $\mathbf{2 . 3 5 4 7 5}$ & $\mathbf{1 . 4 9 2}$ & $\mathbf{2 . 7 9 1}$ \\
\hline ILP & $\mathbf{3 0}$ & $\mathbf{0}$ & $\mathbf{7}$ & $\mathbf{2 . 9}$ & $\mathbf{2 . 0 9 0 2 1}$ & $\mathbf{0 . 7 7 3}$ & $\mathbf{- 0 . 2 3 5}$ \\
\hline
\end{tabular}

Table 2. Basic statistical parameters of asymmetry and normal distribution of specific variables of Superleague in football.

\begin{tabular}{|l|l|l|l|l|l|l|l|}
\hline & $\mathrm{N}$ & Minimum & Maximum & Mean & $\begin{array}{l}\text { Std. } \\
\text { Deviation }\end{array}$ & Skewness & Kurtosis \\
\hline TP & 30 & 10 & 70 & 39.1 & 14.74695 & 0.314 & -0.466 \\
\hline CP & 30 & 8 & 68 & 34 & 14.94357 & 0.458 & -0.32 \\
\hline IP & 30 & 1 & 17 & 5.1 & 3.34612 & 1.818 & 4.398 \\
\hline SHCP & 30 & 8 & 66 & 32.6 & 14.5237 & 0.558 & -0.261 \\
\hline ISHP & 30 & 0 & 10 & 3.3 & 2.35108 & 1.234 & 1.327 \\
\hline ALP & 30 & 0 & 4 & 1.4 & 1.16264 & 0.26 & -0.831 \\
\hline ILP & 30 & 0 & 9 & 1.8 & 1.86437 & 2.159 & 6.679 \\
\hline
\end{tabular}

Total passes (TP), Correct passes (CP), Incorrect passes (IP), Short correct passes (SHCP), Incorrect short passes (ISHP), accurate long passes (ALP) and incorrect long passes (ILP)

On tables 1 and 2 are shown the basic statistical characteristics of the applied specific variables system for league rankings such as Arithmetic Average (AA), Minimum Values, Maximum Values (Max), Standard Deviation (SD) and Asymmetry Parameters ( SKEW and KURT). The minimum and maximum values do not have much difference between the ranks since the results are approximate but there are significant differences in the arithmetic average in some variables such as. TP (Superleague 39.1) (First League 27.1), CP (Superleague 34) (First League 19.7) and SHCP (Superleague 32.6) (First League 17.6) 
Table 3. Correlation coefficients of specific variables of Super League footballers.

\begin{tabular}{|l|l|l|l|l|l|l|l|}
\hline Superleague & TP & CP & IP & SHCP & ISHP & ALP & ILP \\
\hline TP & 1.00 & & & & & & \\
\hline CP & $.975^{* *}$ & 1 & & & & & \\
\hline IP & .054 & -.170 & 1 & & & & \\
\hline SHCP & $.971^{* *}$ & $.997^{* *}$ & -.176 & 1 & & & \\
\hline ISHP & -.171 & $-.357^{*}$ & $.842^{* *}$ & $-.345^{*}$ & 1 & & \\
\hline ALP & $.402^{*}$ & $.395^{*}$ & .007 & $.326^{*}$ & -.285 & 1 & \\
\hline ILP & $.313^{*}$ & .145 & $.733^{* *}$ & .119 & .250 & $.372^{*}$ & 1 \\
\hline
\end{tabular}

Inspection of table 3 of the finite value of Pearson's coefficients shows that the limit value for 30 degrees of freedom ( $\mathrm{df}(\mathrm{N}-2)$ ). Thus, the statistically significant coefficients of the variables with the highest degree of statistical inference $(\mathrm{p}<0.01)$ are denoted by two star signs. Easier criterion of statistical inference $(\mathrm{p}<0.05)$ values are marked with an asterisk.

In realizing the Total Passes, the correct Passes participate in the highest number and constitute the highest percentage with $\mathrm{p}<0.01$, and therefore constitute the first group. The second group comprises the Correct Short Passes with the total passes and the correct passes $p<0.01$.The third group comprises the Inaccurate Short Passes with the inaccurate passes with $p<0.01$.The fourth group comprises the Long Inaccurate Passes with incorrect passes with $p<0.01$.

Table 4. Correlation coefficients of specific variables of First League footballers.

\begin{tabular}{|l|l|l|l|l|l|l|l|}
\hline $\begin{array}{l}\text { First } \\
\text { League }\end{array}$ & TP & CP & IP & SHCP & ISHP & ALP & ILP \\
\hline TP & 1.00 & & & & & & \\
\hline CP & $.980^{* *}$ & 1 & & & & & \\
\hline IP & $.760^{* *}$ & $.616^{* *}$ & 1 & & & & \\
\hline SHCP & $.948^{* *}$ & $.986^{* *}$ & $.532^{* *}$ & 1 & & & \\
\hline ISHP & $.566^{* *}$ & $.424^{* *}$ & $.864^{* *}$ & $.373^{*}$ & 1 & & \\
\hline ALP & $.617^{* *}$ & $.544^{* *}$ & $.680^{* *}$ & $.404^{* *}$ & $.404^{*}$ & 1 & \\
\hline ILP & $.670^{* *}$ & $.573^{* *}$ & $.778^{* *}$ & $.479^{* *}$ & $.383^{*}$ & $.691^{* *}$ & 1 \\
\hline
\end{tabular}

Inspection of this table shows that all the specific motor variables stand statistically in significant correlations: Total Passes with Correct Passes with Incorrect Passes with Correct Short Passes with Incorrect Short Passes with Long Correct Passes with Long inaccurate passes at $\mathrm{p}<0.01$ level. Also, Total Passes, Correct Passes, Incorrect Passes, Short Accurate Passes, Inaccurate Short Passes, Long Accurate Passes, Inaccurate Long Passes are statistically significant at $\mathrm{p}$ $<0.01$. 
Table 5. Differences between arithmetic averages of First League and Super League footballers in specific motor variables

\begin{tabular}{|c|c|c|c|c|c|c|c|c|c|}
\hline \multicolumn{10}{|c|}{ Independent Samples Test } \\
\hline & \multicolumn{9}{|c|}{$\begin{array}{l}\text { Levene's Testt-test for Equality of Means } \\
\text { for Equality } \\
\text { of Variances }\end{array}$} \\
\hline & \multirow[t]{2}{*}{$\mathrm{F}$} & \multirow[t]{2}{*}{ Sig. } & \multirow[t]{2}{*}{$t$} & \multirow[t]{2}{*}{ df } & & \multirow[t]{2}{*}{$\begin{array}{l}\text { Mean } \\
\text { Diff }\end{array}$} & \multirow[t]{2}{*}{$\begin{array}{l}\text { Std. } \\
\text { Error } \\
\text { Diff }\end{array}$} & \multicolumn{2}{|c|}{$\begin{array}{l}95 \% \text { Confidence } \\
\text { Interval of the } \\
\text { Difference }\end{array}$} \\
\hline & & & & & & & & Lower & Upper \\
\hline \multirow{2}{*}{ TP } & .010 & .920 & -3.046 & 58 & .003 & -11.93333 & 3.91767 & -19.77540 & -4.09127 \\
\hline & & & -3.046 & 57.823 & .003 & -11.93333 & 3.91767 & -19.77591 & -4.09076 \\
\hline \multirow{2}{*}{$\mathrm{CP}$} & 1.290 & .261 & -3.948 & 58 & .000 & -14.23333 & 3.60513 & -21.44979 & -7.01688 \\
\hline & & & -3.948 & 56.798 & .000 & -14.23333 & 3.60513 & -21.45304 & -7.01363 \\
\hline \multirow{2}{*}{ IP } & .784 & 380 & 2.464 & 58 & .017 & 2.30000 & .93335 & .43169 & 4.16831 \\
\hline & & & 2.464 & 56.835 & .017 & 2.30000 & .93335 & .43087 & 4.16913 \\
\hline \multirow{2}{*}{ SHCP } & 1.901 & .173 & -4.363 & 58 & .000 & -14.93333 & 3.42269 & -21.78459 & -8.08208 \\
\hline & & & -4.363 & 55.760 & .000 & -14.93333 & 3.42269 & -21.79045 & -8.07622 \\
\hline \multirow{2}{*}{ ISHP } & .241 & .625 & 1.706 & 58 & .093 & 1.10000 & .64461 & -.19032 & 2.39032 \\
\hline & & & 1.706 & 57.267 & .093 & 1.10000 & .64461 & -.19067 & 2.39067 \\
\hline \multirow{2}{*}{ ALP } & 6.181 & .016 & 1.669 & 58 & .101 & .80000 & .47946 & -.15975 & 1.75975 \\
\hline & & & 1.669 & 42.346 & .103 & .80000 & .47946 & -.16736 & 1.76736 \\
\hline \multirow{2}{*}{ ILP } & 1.441 & .235 & 2.151 & 58 & .036 & 1.10000 & .51137 & .07639 & 2.12361 \\
\hline & & & 2.151 & 57.258 & .036 & 1.10000 & .51137 & .07611 & 2.12389 \\
\hline
\end{tabular}

In the Total Passes between the First League and Superleague players there is a statistically significant difference $\mathrm{p}<0.003$ because the difference is at -11.93 passes. Superleague players have been better.

There was a statistically significant difference $\mathrm{p}<0.000$ in the Exact Passes between the First League and Superleague players because the difference is at -14.23 passes. Superleague players have been better. In the incorrect passes between the First League and Superleague players there is a statistically significant difference $\mathrm{p}<0.017$ because the difference is at 2.30 passes. Superleague players have had fewer inaccurate passes. There was a statistically significant $\mathrm{p}$ $<0.000$ difference between the First League and Superleague players in the precise short passes because the difference is at -14.93 passes. Superleague players have been better. In the incorrect passes between the First League and Superleague players there is no statistically significant difference $\mathrm{p}<0.093$ because the difference is at 1.10 passes. Superleague players have had fewer inaccurate short passes. There was no statistically significant difference $p<0.101$ in the long accurate passes between the First League and Superleague players because the difference was at 
0.80 passes. Superleague players have had fewer accurate long passes. In the long incorrect passes between the First League and Superleague players there is a statistically significant difference $\mathrm{p}<0.036$ because the difference is at 1.10 passes. Superleague players have had fewer long incorrect passes.

\section{CONCLUSION}

Efficiency in the game of football is possible only if phenomena is systematically defined as it is of primary importance for structuring the basic movements and the technical-tactical elements in the game of football. Processing these matches in a "turkey epor" software. This program extracts information or data on the types and number of team and player passes, the percentage of team efficiency and each team player that has been the subject of research.

Since there has never been a technical survey of football players in Kosovo (passes) then I found it very important to do so. This research will serve all those who want to know the performances of a midfielder during a championship match. Such a study will probably in the future give way to many more detailed studies not only in the pass element but also in other technical and tactical features of the players regardless of their role on the pitch.

The main purpose of this research is to compare the midfielders of the Superleague and the First League in the technical element of the pass which is very significant for the quality of a player specifically a midfielder.

\section{Data processing shows that:}

Superleague midfielders have shown better results both in number of passes and in accuracy. In total passes, in short correct passes, long correct passes Superleague midfielders have more passes while in inaccurate passes, inaccurate short passes and long inaccurate passes they have less inaccurate passes which was expected even before this research.

\section{References}

1.Hook, C., and Hughes, M. (2001). "Patterns of play leading to shots in "euro 2000," in Center for Performance Analysis, ed. Pass.com (Cardif: UWIC)

2. A. Casal1 *, Rubén Maneiro2, Toni Ardá3, Francisco J. Marí4 and José L. Losada4 . Frontiers in psychology. Possession Zone as a Performance Indicator in Football. The Game of the Best Teams Claudio.

3.P. D. Jones, N. James and S. D. Mellalieu Department of Sports Science, University of Wales Swansea, Vivian Tower, Singleton Park, Swansea SA2 8PP, Wales, UK. Possession as a Performance Indicator in Soccer Article in International Journal of Performance Analysis in Sport

4.Ridgewell A. Passing patterns before and after scoring in the 2010 FIFA World Cup. International Journal of Performance Analysis in Sport. 2011 Dec 1; 11(3):562-74

5.Ali, A. and Farrally, M., 1990, A computer-video aided time motion analysis technique for match analysis. Journal of Sports Medicine and Physical Fitness, 31, pp. 82- 88. 
6.Franks, I.M. and McGarry, T., 1996, The science of match analysis. In T. Reilly (ed.). Science and Soccer. E. \& F.N. Spon, London, pp. 363-375.

7.Paixão P, Sampaio J, Almeida $\mathrm{CH}$, Duarte R. How does match status affects the passing sequences of top-level European soccer teams? International Journal of Performance Analysis in Sport. 2015 Mar 1; 15(1):229-40.

8.Lago C, Mart1'n R. Determinants of possession of the ball in soccer. Journal of sports sciences. 2007 Jul 1; 25(9):969-74. https://doi.org/10.1080/02640410600944626 PMID: 17497397

9.Di Salvo, V. (6 October 2005). "Performance characteristics according to playing position in elite soccer". International Journal of Sports Medicine. 28 (3): 222-7. doi:10.1055/s-2006924294. PMID 17024626.

10.Hughes M, Franks I. Analysis of passing sequences, shots and goals in soccer. J Sport Sci. 2005;23:509-514. [PubMed] [Google Scholar]

11.Lago-Penas C, Lago-Ballesteros J, Rey E. Differences in Performance Indicators between Winning and Losing Teams in the UEFA Champions League. J Hum Kinet. 2011;27:137-48.

12. Robert Rein , Dominik Raabe, Daniel Memmert "Which pass is better?" Novel approaches to assess passing effectiveness in elite soccer. Human Movement Science Volume 55, October 2017, Pages 172-181

13. Michael C. RUMPF 1, 2 , Joao R. SILVA 1, 3, Maxime HERTZOG 1, Abdulaziz FAROOQ 4, George NASSIS 1 Technical and physical analysis of the 2014 FIFA World Cup Brazil: winners vs. losers. The Journal of Sports Medicine and Physical Fitness 2017 October;57(10):1338-4

14. https://www.worldatlas.com/articles/what-are-the-most-popular-sports-in-the-world.html

15. http://ffk-kosova.com/historiku/

16. https://www.footy4kids.co.uk/soccer-drills/tactics/the-job-of-a-midfielder/\#

17. https://www.premierleague.com/news/834597

18. https://totalfootballanalysis.com/player-analysis/tactical-analysis-ilkay-gundoganmanchester-city-premier-league-analysis 